\title{
Kinetic Study for the Synthesis of Diethyl Maleate over Cation Exchange Resin Indion 730
}

\author{
Rajkumar S. Sirsam and Ghayas A. Usmani
}

\begin{abstract}
Kinetic study of the esterification of maleic acid with ethanol has been carried out over cation exchange resin Indion 730, Indion 225H, AmberliteIR120, Amberlyst 35 wet. Indion 730 has shown the higher conversion of maleic acid than other catalyst. Effect of various parameters such as speed of agitation (600- $1000 \mathrm{rpm})$, particle size $(0.172-0.834 \mathrm{~mm})$, mole ratio (maleic acid to ethanol, 1:4 - 1:10), catalyst loading $\left(50-120 \mathrm{~kg} / \mathrm{m}^{3}\right.$ of reactant volume), temperature $(323-353 \mathrm{~K})$ has been studied. A psudo homogeneous model has been applied to validate the experimental data at different temperature and activation energy was found to be $12.54 \mathrm{kcal} / \mathrm{mol}$.
\end{abstract}

Index Terms-Activation energy, esterification, indion 730, kinetics.

\section{INTRODUCTION}

Organic Esters have been extensively used in the production of latex emulsion polymers, thermoplast and thermoset plastics and used as solvents, perfumery, flavor chemicals pharmaceuticals, agrochemicals and other fine chemicals [1]. Diethyl maleate (DEM) can be prepared by treating ethanol with maleic anhydride in the liquid phase either with a monoester intermediate stage or by a direct route or by using maleic acid. Esterification is a very widely employed reaction in the organic process industry. Ester falls under a very wide category ranging from alipahatic or aromatic with various substitution and multifunctional group.

In esterification various inorganic and organic acids have been used as catalyst [2]. Though these catalysts are economical but it influences the cost of downstream processes. For more effective processes the uses of heterogeneous catalysts such as zeolites, metal oxides, acid treated clays, cation-exchange resins, etc., are being exploited as the replacement due to their eco-friendly nature [3], [4]. Cation exchange resin catalyzed reactions is extensively been reviewed [5].

The esterification of maleic acid with ethanol in presence of cation exchange resin can be represented as follows:

\section{$\mathrm{HCOOCHCHCOOH}+2 \mathrm{C} 2 \mathrm{H} 5$ $\mathrm{C} 2 \mathrm{H} 5 \mathrm{COOCHCHCOOC} 2 \mathrm{H} 5+2 \mathrm{H} 2 \mathrm{O}$}

The above esterification reaction assumed to be occurred in two steps, first step is the formation of monoester and second one is reaction of monoester with another ethanol

Manuscript received April 20, 2013; revised June 4, 2013.

The authors are with the University Institute of Chemical Technology, North Maharashtra University, Jalgaon-425001, India (e-mail rajkumarsirsam@gmail.com). molecule. The former step assumed faster as compare to latter [6]. As the reaction is reversible, either one of the products is removed continuously or ethanol is kept always in excess to shift the equilibrium towards the product. This paper presents the kinetic study of the reaction in presence of cation exchange resin. The effect of various parameters such as speed of agitation, particle size, temperature, catalyst loading and acid to alcohol molar ratio has been investigated.

\section{Materials AND Methods}

\section{A. Materials}

Industrial grade ethanol $(95 \% \mathrm{v} / \mathrm{v})$ was used for all experimental runs. Maleic acid, cation exchange resins Indion 730, Indion 225H, Amberlite IR120, Amberlyst 35 wet, $\mathrm{KOH}$ was obtained from s. d. fine Chemicals, Mumbai, INDIA. All the catalysts were dried at $120^{\circ} \mathrm{C}$ for 5 hours before being used.

\section{B. Analysis}

Sample collected at different time interval were analyzed chemically as well as by Gas chromatography. The chemical analysis of maleic acid was performed independently by titration using $0.1 \mathrm{~N}$ alcoholic $\mathrm{KOH}$ [6]. Gas chromatography analysis of samples was carried out by TSQ Quantum GC-MS for confirmation; model TSQ Quantum (Triple Quadrapole), Column TR wax MS/TR5 MS (30 m × $0.25 \times$ 0.25 ) with hydrogen as carrier gas at flow rate of $35 \mathrm{ml} / \mathrm{min}$. Injector and detector temperature were maintained at $373 \mathrm{~K}$ and $323 \mathrm{~K}$ respectively. Oven temperature was programmed to get best resolution and the least time for analysis. Oven temperature was initially maintained at $323 \mathrm{~K}$ for 1 minute and then increased at a rate of $298 \mathrm{~K} / \mathrm{min}$ upto $473 \mathrm{~K}$ and maintained for 1 minute and again increased at a rate of 288 $\mathrm{K} / \mathrm{min}$ upto $500 \mathrm{~K}$ and maintained there for 2 minutes. The retention time for maleic acid was confirmed by the pure sample.

\section{Apparatus and Procedure}

Batch experiments were carried out in a mechanically agitated contactor $2.5 \times 10^{-4} \mathrm{~m}^{3}$ capacity provided with reflux condenser on the top of the reactor in order to prevent the escape of volatile compounds. The reactor was immersed in constant temperature bath. The bath temperature was maintained within $\pm 1 \mathrm{~K}$ of the set point. The desired amount of reactant maleic acid and ethanol were charged into the reactor. The reaction mixture was allowed to attend the desired temperature, this was considered zero time for the reaction and then catalyst was added to the reactor. The samples were withdrawn at specified time interval and 
analyzed. The effect of catalyst type, feed mol ratio (maleic acid to ethanol), catalyst loading and temperature were studied.

\section{RESUlTS AND DISCUSSION}

\section{A. Catalyst Study}

Effectiveness of various solid catalyst such Indion 730, Indion 225H, AmberliteIR120, Amberlyst 35 wet, have been studied. Desired amount of maleic acid and ethanol (mole ratio maleic acid:ethanol; 1:5) was taken in the reactor. A catalyst loading of $80 \mathrm{~kg} / \mathrm{m}^{3}$ of reaction volume was employed in the reaction mixture at $353 \mathrm{~K}$. Stirring speed was kept at $1000 \pm 10 \mathrm{rpm}$. Fractional conversion of maleic acid with respect to time has been plotted in Fig. 1. It has been observed that Indion 730 shows highest conversion amongst other catalyst. Further experiments were carried out with catalyst Indion 730 under otherwise similar condition except one parameter.

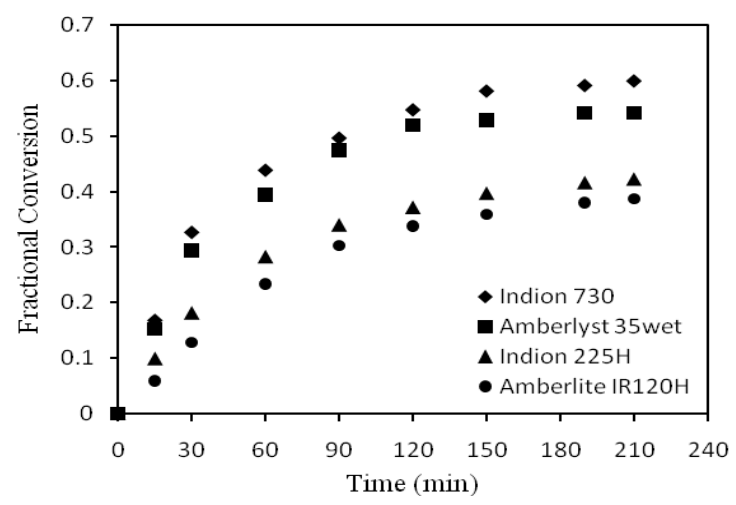

Fig. 1. Effect of different catalyst: Speed of agitation: $100 \mathrm{rpm}$; Catalyst loading: $80 \mathrm{~kg} / \mathrm{m}^{3}$; Effective particle size: $0.45-0.60 \mathrm{~mm}$; Mole ratio (Acid:Alcohol): 1:8; temperature: $353 \mathrm{~K}$.

\section{B. Elimination of Mass Transfer Resistance}

The reaction in presence of cation exchange resin is typical solid-liquid slurry reaction involving transfer of maleic acid from bulk liquid phase to catalyst surface wherein external mass transfer of reactants to surface of the catalyst particle, followed by intra-particle diffusion, adsorption, surface reaction and desorption take place. To study the kinetics of the reaction, the influence of the external mass transfer resistance and intra-particle diffusion resistance must be established. The effect of external diffusion limitation on the esterification reaction rate was studied by several workers [6] [7]. To study the external diffusion effect on the reaction rate, reaction was carried out at sufficiently high stirrer speed (600-1000 rpm). If the fractional conversion of maleic acid is independent of stirrer speed, it implies that the external diffusion is not the rate controlling step.

From fig. 2 it has been observed that fractional conversion of maleic acid does not depend upon the speed of agitation. Hence, the effect of external mass transfer resistance can be neglected and all the further runs were conducted at 1000 rpm.

Available resin particles were screened in the range of $0.178 \mathrm{~mm}-0.834 \mathrm{~mm}$. To study the effect of particle experiments were performed under otherwise similar conditions. It confirms, from figure 3, that the intra-particle diffusion over the range of particle size studied are negligible. While changing the particle size, the rate of reaction doesn't change appreciably. Several workers have reported that intra-particle diffusion resistances of the reactant in the ion exchange resin are not important [8]-[10]. Hence, all the further experiments were conducted by using available resin with effective particle size of $0.45 \mathrm{~mm}-0.60 \mathrm{~mm}$.

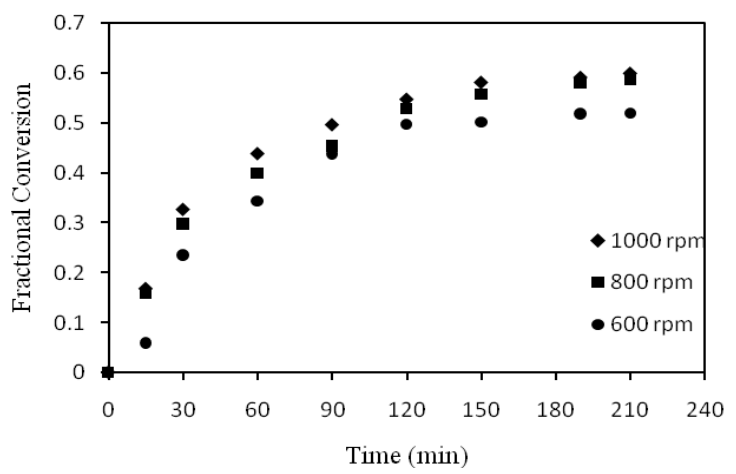

Fig. 2. Effect of speed of agitation: Catalyst: Indion 730; Effective particle size: 0.45-0.60 mm; Catalyst loading: $80 \mathrm{~kg} / \mathrm{m}^{3}$; Mole ratio (Acid:Alcohol): $1: 8$; temperature: $353 \mathrm{~K}$.

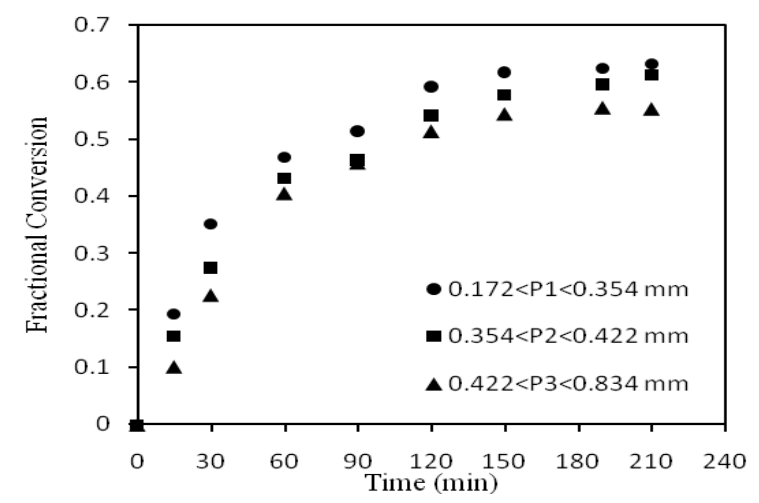

Fig. 3. Effect of particle size: Catalyst: Indion 730; speed of agitation: 100 rpm; Catalyst loading: $80 \mathrm{~kg} / \mathrm{m}^{3}$; Mole ratio (Acid:Alcohol): 1:8; temperature: $353 \mathrm{~K}$.

\section{Effect of Mole Ratio}

The effect of maleic acid to ethanol molar ratio was investigated by varying the acid to alcohol molar ratio ranging from 1:4 to 1:10 under otherwise similar condition of particle size, catalyst loading, temperature, stirring speed. As the ethanol in reaction mixture taken in excess, the rate of reaction increases and it confirms that the equilibrium shifts towards the formation of DEM. From fig. 4, it was observed that increasing the amount of alcohol increases the conversion of acid. There was no significant difference in the final conversion of maleic acid at molar ratio of $1: 8$ and $1: 10$. Therefore, at existing operating condition molar ratio of $1: 8$ has been taken for further experiments.

\section{Effect of Catalyst Loading}

The effect of catalyst loading of Indion 730 on the conversion of maleic acid was studied by varying the catalyst loading $50 \mathrm{~kg} / \mathrm{m}^{3}$ to $120 \mathrm{~kg} / \mathrm{m}^{3}$ of total volume of reactant. As can be seen from figure 5 , fractional conversion of maleic acid to DEM has been increased with increasing catalyst loading. As recorded by several workers, G. Yadav [6], S. 
Chopade [11], S. H. Ali [12], that increasing the catalyst loading means more available active sites for the reaction, which results in higher reaction rate. The difference in fractional conversion of maleic acid at catalyst loading of 80 $\mathrm{kg} / \mathrm{m}^{3}$ and $120 \mathrm{~kg} / \mathrm{m}^{3}$ is not significant. Therefore, at existing operating condition at catalyst loading of $80 \mathrm{~kg} / \mathrm{m}^{3}$ has been taken for further experiments.

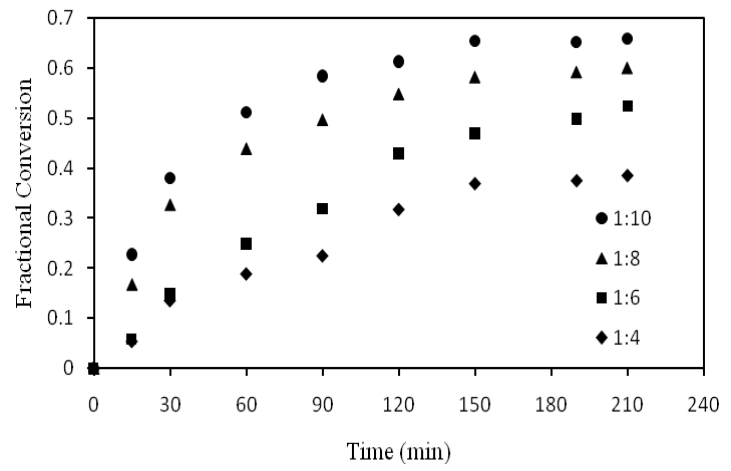

Fig. 4. Effect of mole ratio: Catalyst: Indion 730; speed of agitation: $100 \mathrm{rpm}$; Effective particle size: $0.45-0.60 \mathrm{~mm}$; Catalyst loading: $80 \mathrm{~kg} / \mathrm{m}^{3}$; temperature: $353 \mathrm{~K}$.

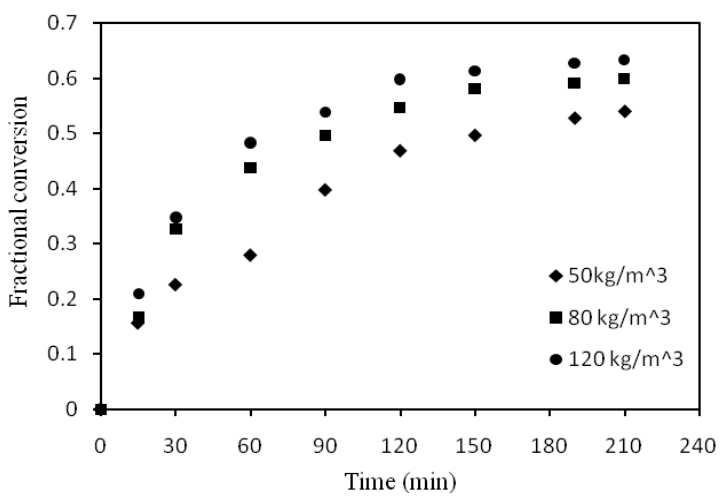

Fig. 5. Effect of catalyst loading: Catalyst: Indion 730; speed of agitation: $100 \mathrm{rpm}$; Effective particle size: $0.45-0.60 \mathrm{~mm}$; mole ratio: $1: 8$; temperature: $353 \mathrm{~K}$.

\section{E. Kinetic Model}

Various kinetic models have been described for liquid phase reactions catalyzed by ion exchange resin such as pseudo-homogeneous (PH) model, Langmuir-Hinshelwood (LHW) model, Eley-Rideal (ER) model in the absence of any intra-particle diffusion limitations [5]. A pseudohomogeneous approach has been used to explain kinetic data. As mentioned earlier the reaction was assumed to be proceeds in two steps as shown below by Eqs. (2) and (3):

$$
\begin{aligned}
& M A+E \leftrightarrow M E E+W \\
& M E E+E \leftrightarrow D E M+W
\end{aligned}
$$

As the first step is much faster, at any time the concentration of monoethyl ester (MEE) can be considered to be in equilibrium with maleic acid (MA) and ethanol (E). Hence, the concentration of MEE by steady state approximation is:

$$
C_{M E E}=K \frac{C_{M A} C_{E}}{C_{W}}
$$

$$
\begin{gathered}
C_{M A}=C_{M A 0}\left(1-X_{M A}\right) \\
C_{E}=C_{M A 0}\left(M-2 X_{M A}\right)
\end{gathered}
$$

where $M$ is initial molar ratio of $C_{B O}$ to $C_{M A O}$

$$
\begin{aligned}
& C_{D E M}=C_{M A 0} X_{M A} \\
& C_{W}=2 C_{M A 0} X_{M A}
\end{aligned}
$$

The rate of reaction of maleic acid can be represented as:

$$
\begin{aligned}
& \frac{d C_{M A}}{d t}=k^{\prime} C_{M E E} C_{E}-k_{2} C_{D E M} C_{W} \\
& \frac{d C_{M A}}{d t}=k^{\prime} K \frac{C_{M A} C_{E}^{2}}{C_{W}}-k_{2} C_{D E M} C_{W}
\end{aligned}
$$

Let $k_{l}=k^{\prime} K$, forward reaction rate constant

$$
\frac{d C_{M A}}{d t}=k_{1} \frac{C_{M A} C_{E}^{2}}{C_{W}}-k_{2} C_{D E M} C_{W}
$$

Eq. (11) can be written in terms of conversion of maleic acid $X_{M A}$ by using Eqs. (5) - (8) as:

$$
\begin{aligned}
& C_{M A 0}\left(\frac{d X_{M A}}{d t}\right)= \\
& \quad k_{1} C_{M A 0}^{2}\left[\frac{C_{M A 0}\left(1-X_{M A}\right)\left(M-2 X_{M A}\right)^{2}}{2 C_{M A 0} X_{M A}}-2 \frac{X_{M A}^{2}}{K}\right]
\end{aligned}
$$

As mentioned earlier, ethanol was taken in excess to shift the equilibrium towards product side, the rate of backward reaction is negligible and hence the overall reaction was considered to be an irreversible reaction. Therefore Eq. (12) can be deduced as:

$$
\frac{d X_{M A}}{d t}=k_{1} C_{M A 0}\left[\frac{\left(1-X_{M A}\right)\left(M-2 X_{M A}\right)^{2}}{2 X_{M A}}\right]
$$

Eq. (13) can be integrated for $M$ not equal to 1 and 2.

$$
\frac{2}{(M-2)}\left\{\begin{array}{l}
\frac{1}{(M-2)} \ln \left[\frac{M}{\left(M-2 X_{M A}\right)}\right]- \\
\ln \left(1-X_{M A}\right)-\frac{2 X_{M A}}{\left(M-2 X_{M A}\right)}
\end{array}\right\}=k_{1} C_{M A 0} t=k_{1}^{\prime} t
$$

\section{F. Effect of Temperature}

The effect of temperature on the rate of reaction of maleic acid was studies over the range of 323 - $353 \mathrm{~K}$ under otherwise similar conditions. The kinetic energy of the molecules increases at higher temperature, and also the number of collisions, resulting into higher conversion rate. From Fig. 6 it confirms that the rate of formation of DEM increases with increasing temperature.

L. H. S. of Eq. (14) is plotted against time (Fig. 7), which suggests that the model developed for the system is suitable 
to represent the experimental data for different temperature. The slope of the straight line gives the value of $k_{l}^{\prime}$, from which reaction rate constant $k_{l}$ was determined. The Arrhenius equation is plotted (Fig. 8) to get activation energy as $12.54 \mathrm{kcal} / \mathrm{mol}$.

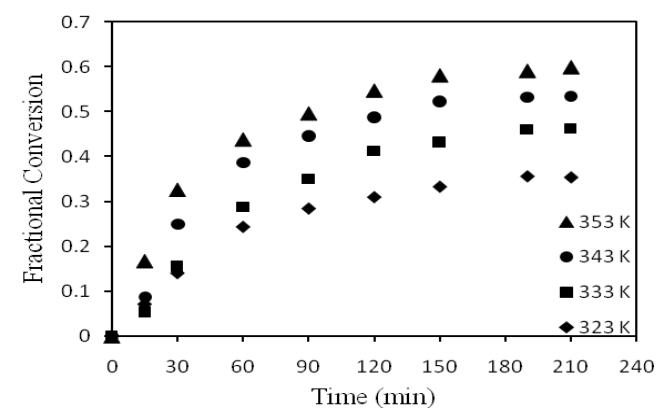

Fig. 6. Effect of temperature: Catalyst: Indion 730; speed of agitation: 100 $\mathrm{rpm}$; Effective particle size: $0.45-0.60 \mathrm{~mm}$; mole ratio: 1:8; Catalyst loading: $80 \mathrm{~kg} / \mathrm{m}^{3}$

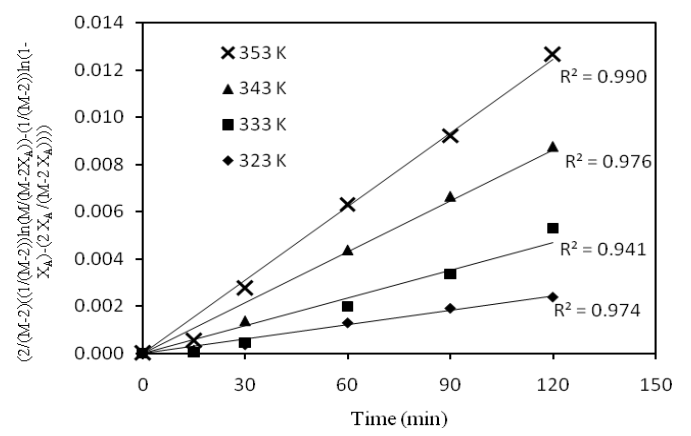

Fig. 7. Kinetic plot for the effect of temperature: Catalyst: Indion 730; speed of agitation: $100 \mathrm{rpm}$; Effective particle size: $0.45-0.60 \mathrm{~mm}$; mole ratio: 1:8; Catalyst loading: $80 \mathrm{~kg} / \mathrm{m}^{3}$

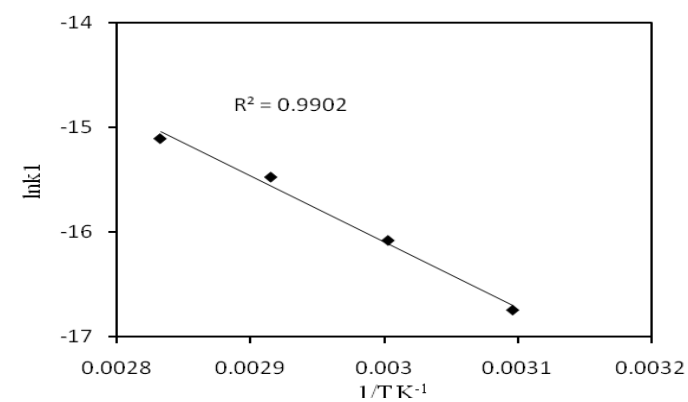

Fig. 8. Arrhenius plot of $\ln k_{l}$ vs. 1/T: Catalyst: Indion 730; speed of agitation: $100 \mathrm{rpm}$; Effective particle size: $0.45-0.60 \mathrm{~mm}$; mole ratio: 1:8; Catalyst loading: $80 \mathrm{~kg} / \mathrm{m}^{3}$

\section{CONCLUSION}

Different catalyst have been used to study the esterification of maleic acid with ethanol, Indion 730, Amberlyst 35 wet, Indion 225H, AmberliteIR120. Indion 730 was used for further study. A pseudo-homogeneous kinetic model was developed and employed to fit the experimental data and the activation energy was found to be $12.54 \mathrm{kcal} / \mathrm{mol}$.

\section{REFERENCES}

[1] S. Kirumakki, N. Nagaraju, and N. Sankarasubbier, "A comparative esterification of benzyl alcohol with acetic acid over zeolites H $\beta, \mathrm{HY}$ and HZSM5," Appl. Catal. A Gen., vol. 273, pp. 1-9, 2004.

[2] O. D. L. Iglesia, R. Mallada, and M. Coronas, "Continuous zeolite membrane reactor for esterification of ethanol and acetic acid," Chem. Engg. J., vol. 131, pp. 35-39, 2007.

[3] S. Kirumakki, N. Nagaraju, and V. R. C. Komandur, "Esterification of benzyl alcohol with acetic acid over zeolites H $\beta$, HY and HZSM5," Appl. Catal. A. Gen, vol. 299, pp. 185-192, 2006.

[4] T. Thorat, V. Yadav, and G. Yadav, "Esterification of pthalic anhydride with 2-ethylhexanol by solid superacidic catalysts," Appl. Catal. A. Gen, vol. 90, pp. 73-96, 1992.

[5] A. Chakrabati and M. Sharma, "Cationic ion exchange resins as catalyst," React. Polym, vol. 20, pp. 1-45, 1993.

[6] G. Yadav and M. Thathagar, "Esterification of maleic acid with ethanol over cation-exchange resin catalysts," React Funct Polym, vol. 52, pp. 99-110, 2002.

[7] K. D. Rao and M. Bhagwat, "Kinetics of esterification of n-propyl alcohol with acetic acid catalyzed by Dowex-50," Indian J. Technol, vol. 22, pp. 268-271, 1984.

[8] G. Yadav and H. Kulkarni, "Ion-exchange resin catalysis in the synthesis of isopropyl lactate," React Funct Polym, vol. 44, pp. 153, 2000.

[9] H. T. R. Teo and B. Saha, "Heterogeneous catalysed esterification of acetic acid with isoamyl alcohol: Kinetic studies," J. Catal, vol. 228, pp. 174-182, 2004.

[10] I. Alime and F. Bodur, "Liquid-phase esterification of acetic acid with isobutanol catalyzed by ion-exchange resins," React Funct Polym, vol. 67, pp. 1458-1464, 2007.

[11] S. Chopade and M. Sharma, "Reaction of ethanol and formaldehyde: use of versatile cation-exchange resins as catalyst in batch reactors and reactive distillation column," React Funct Polym, vol. 32, pp. 53-64, 1997.

[12] S. Ali, T. Alia, Q. Sabiha, and T. A. Sahhaf, "Synthesis of esters: development of the rate expression for the dowex 50 wx 8-400 catalyzed esterification of propionic acid with 1-propanol," vol. 62, pp. 3197-3217, 2007.

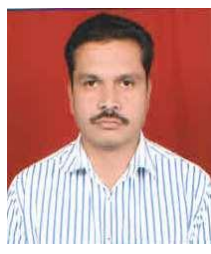

Rajkumar Sirsam was born at Wai (khurd), District Amravati (MS) India, on 28 December, 1975. He has got his bachelor degree B. Tech (Chem Engg.) in 1999 from Laxminarayan Institute of Technology, R.S. T. M. Nagpur University, India. In 2003, he has got his master degree M. Tech (Petroleum Refining \& Petrochemical Technology) from same institute. $\mathrm{He}$ presently work as Associate professor at University Institute of Chemical Technology, North Maharashtra University, Jalgaon, India. He is working on minor research project funded by University Grant Commission, New Delhi, India. He had published his research work in national and international journal and also presented paper at national and international conferences.

Ghayas Usmani was born on 12 March, 1964. He has got his bachelor degree B. Tech (Chem. Engg.), master's degree M. Tech (Oil Tech.) and Ph. D. (Oil Tech.) from HBTI, Kanpur, India. He is presently working as associate professor at University Institute of Chemical Technology, North Maharashtra University, Jalgaon, India. He had completed several research project funded by University Grant Commission, New Delhi, India, All India Council for Technical Education, New Delhi, India. He had presented and published his research papers in several seminars and journals 